\title{
Utilization of Integrated Management of Neonatal and Childhood Illness (IMNCI) Guidelines and Associated Factors among Nurse at Public Health Institutions in West Arsi Zone, South East Ethiopia
}

\author{
Sheka Shemsi Seid ${ }^{1}$, Endalew Gemechu Sendo ${ }^{2}$, Tura Koshe Haso ${ }^{1}$ and Shamsedin Amme ${ }^{1}$ \\ ${ }^{1}$ Department of Nursing and Midwifery, Institute of Health, Jimma University, Ethiopia; ${ }^{2}$ Department of Nursing, School of Allied \\ Health Sciences, Addis Ababa University, Ethiopia
}

\begin{abstract}
Background: World health organization (WHO) and United Nations for Children's Fund (UNICEF) in the early 1990s developed Integrated Management of Childhood Illness (IMCI), a strategy designed to reduce child mortality and morbidity in developing countries. This study is aimed at assessing factors associated with utilization of IMNCI protocol by nurses West Arsi Zone, Oromia Region, Ethiopia.

Methods: An institutional based cross-sectional study was conducted on a total of 185 nurses who were included from health facilities selected using simple random sampling technique. Data was coded, entered and cleaned using Epi-data 3.1 and exported to SPSS version 22 for analysis. Univariate and bivariate analysis was performed. Multivariate analysis was also done to control for possible confounding variables.

Results: Data were obtained from 185 nurses, of which 131 (70.8\%) were males. More than half 103 (55.7\%) of the respondents was aged between 25-29 years. The mean $( \pm$ SD) age was $26.65 \pm(1.7)$ with the range of 20-43 years and 107 (57.8\%) were diploma nurses. The overall IMNCI protocol utilization was $58.7 \%$. In multivariate analysis, the odd of IMNCI utilizations among nurses who had attended IMNCI training were 2.76 times higher compared to nurses who had not attended IMNCI training [AOR=2.76, 95\% CI:1.388, 5.51]. Nurses who had practice of always referring chart booklet during every case management process were three times more likely to utilize IMNCI protocols $[\mathrm{AOR}=2.95,95 \% \mathrm{CI}: 1.48,5.89]$ compared to their counterparts.

Conclusions: The proportion of IMNCI utilizations in the selected districts was low and less than the WHO recommendations. Training and frequent referring of chart booklet were found to significantly associate with the utilization of the IMNCI protocols. Therefore the emphasis should be given to the provision of IMNCI training to the nurse by the stakeholders and motivating the nurses to always refer chart booklet, in order to enhance proper utilization of the protocols.

Keywords: Public heath instructions; Nurses; IMCI; Arsi; Ethiopia
\end{abstract}

\section{INTRODUCTION}

The Integrated Management of Childhood Illness (IMCI) is a comprehensive approach to child health that focuses on the wellbeing of the whole child and aims to reduce death, illness and disability, and to promote improved growth and development among children under five years of age [1].
In health facilities, the IMCI strategy enhances the correct identification of childhood illnesses in outpatient settings, ensures appropriate combined treatment of all major illnesses, strengthens the counseling of caretakers, and speeds up the referral of severely ill children. In the home setting, it promotes appropriate care seeking behaviors, improved nutrition and

"Correspondance to: Sheka Shemsi Seid, Department of Nursing and Midwifery, Institute of Health, Jimma University, Ethiopia, Tel: 251-917-513-841; E-mail: shekaa2006@gmail.com

Received date: November 28, 2018; Accepted date: December 27, 2018; Published date: January 02, 2019

Citation: Seid SS, Sendo EG, Haso TK, Amme S. Utilization of integrated management of neonatal and childhood illness (IMNCI) guidelines and associated factors among nurse at public health institutions in west arsi zone, South East Ethiopia. Clinics Mother Child Health. 2019;16:313. doi: 10.24105/2090-7214.1000313

Copyright: (C) 2019 Seid SS, et al. This is an open-access article distributed under the terms of the Creative Commons Attribution License, which permits unrestricted use, distribution, and reproduction in any medium, provided the original author and source are credited. 
preventative care, and the correct implementation of prescribed care $[2,3]$.

Ethiopia has one of the highest under-five mortality rates with more than 321,000 Children under the age of five dying every year. More than seventy percent of these are attributed to preventable and curable causes of deaths which includes pneumonia, diarrhea, malaria, measles and malnutrition, and often to a combination of these conditions. As children usually present with more than one of these conditions, it was recognized that there was a need for an integrated approach in order to manage the child in a holistic manner. This led to the development of the Integrated Management of Newborn and Childhood Illness (IMNCI) strategy [4].

IMNCI includes both preventive and curative elements that are implemented by families and communities as well as by health facilities. In summary, the IMNCI strategy includes three main components these include: Improving case management skills of healthcare staff, improving the health systems and improving family and community health practices $[3,5-6]$.

Ethiopia adopted the IMCI strategy in 1996 in attempt to reduce the infant and under-five mortality rates [4]. Health facility surveys carried out in three regional states of Ethiopia: Amhara, Oromia and Southern Nations and Nationalities Peoples'(SNNP) indicated low utilization of IMCI in the regions. IMCI coverage was 20\% for Amhara, 4\% for Oromia, and 25\% for SNNP Region. Inadequate supervision, shortage of consultation time and lack of training on the protocol utilizations were identified as factors affecting utilization IMNCI protocols [7].

IMNCI has been utilized in Ethiopia since 1996, however, there is limited documents regarding factors affecting utilization of IMNCI protocol. The researcher believes that the scarcity of available data on this topic in the study area has limited the development of intervention strategies in line with Millennium developmental goal four and Sustainable developmental goal. Hence, this study is aimed at assessing factors associated with utilization of IMNCI protocol by nurses West Arsi Zone, Oromia Region, Ethiopia.

\section{METHODS AND MATERIALS}

\section{Study area and period}

The study was conducted from February to March 2016 in West Arsi zone of Oromia regional state, which is found at South East, Ethiopia. The zone has an area of $12556 \mathrm{Km}^{2}$, which comprises 12 districts and 3 towns administration. Shashamenne is the zonal town which is $251 \mathrm{~km}$ far from capital Addis Ababa. The zone has 84 public health institutions (one zonal and two district Hospital, and eighty one Health center) and other one Non-Governmental Organization (NGO) hospital and private health institutions in the zone. The total 850 of nurses were providing health care service in public health institution of the zone. It is one the zones in Oromia regional state having a high number of under-five mortality rate. More than eighty five percent of under-five children are presented at governmental institutions and it is due to this reason that the researchers interested in government owned health facilities. Four districts having high under-five mortality rate were purposively selected for this research from the 12 districts. The selected districts had a total of 291 registered nurses.

\section{Study design}

A facility based descriptive cross sectional study was used.

\section{Sampling size, sampling technique and procedures}

Since it is impossible to include all nurse in selected districts due to financial, time and other resources constraints, the sample size was calculated based on the sloven's formula which is used where the prevalence is not required or known [8].

$\mathrm{n}=(\mathrm{N} / 1+(\mathrm{e}) 2)$

Where: $n=$ sample size, $N=$ population size (total number of nurses in four districts in this study)

$\mathrm{e}=$ sampling error (which is assumed to be $5 \%$ i.e. $95 \% \mathrm{CI}$

$\geq(291 / 1+291(0.05) 2)=168$

By considering $10 \%$ non-respondent rate the final sample was 185.

First step: Four districts having high under-five mortality rate were purposively selected among 12 districts. Second step: the determined sample size was proportionally allocated each district based on their respective number of nurses. The proportional allocation for each district was 46 for Shashamane, 57 for Arsi Negele, 44 for Shalla and 38, for Dodola district. Finally, systematic sampling method was used to select study units from list of human resource profile of health facilities.

\section{Data collection tool and procedure}

Data was collected by using, structured self-administered questionnaires which was mainly adopted from WHO tool to evaluate the quality of care taker delivered to sick children attending outpatient facilities and challenges identified by experienced IMCI-1-trained registered nurses in implementing the Integrated Management of Childhood Illnesses (IMCI) Strategy in English version $[9,10]$. The questionnaire consists of socio-demographic information, factors affecting utilization of IMNCI by nurses. The quality of the data collected was guaranteed by pretesting being done on $5 \%$ nurses (in Siraro districts health center) and essential modifications then was made. The researchers trained the data collectors on how to collect data from the records to augment data accuracy and validity. The collected data was reviewed and checked for its' completeness before data entry. There was close supervision of the data collectors by the principal investigators.

\section{Data analysis}

Data collected were coded and entered into Epi Data 3.1 and exported to SPSS version 22.0 for cleaning and analysis. Data were summarized using simple frequency tables, graphs, and charts. Bivariate analysis was done and Independent variables which had a P-value of less than 0.25 in bivariate analysis were 
entered to multivariate analysis to assess the relative effect of independent variables on dependent variables, with significance at $\mathrm{P}$-value less than 0.05 .

\section{Ethical consideration}

Ethical clearance was obtained from Addis Ababa University (AAU), College of Health Science, and Department of Nursing and Midwifery Institutional Review Board (IRB) research committee and official letter was written to Oromia region health bureau and permission letter was obtained from West Arsi zone health office. Informed consent was obtained from a respondent who was participated in the study. The participation in this study is voluntary; they can also withdraw at any time from the study if they feel uncomfortable. Refusal to participate will not affect their work or care they shall seek at any of the health facilities in any way. Confidentiality was maintained by omitting their name and personal identification and participant was not compelled to the study.

\section{RESULTS}

\section{Sociodemographic characteristics}

A total of 185 nurses were involved in the study providing response rate of $100 \%$. Among the study population 131 (70.8\%) were males. More than half 103 (55.7\%) of the respondents was aged between $25-29$ years. The mean $( \pm$ SD) age was $26.65 \pm(1.7)$ with the range of $20-43$ years. With regard to level of qualification 107 (57.8\%) were diploma nurses while 74 (40\%) were BSc nurses. Among the study participants 103 (55.7\%) were currently married and the majority, 163 (88.1\%) were belong to Oromo ethnic group (Table 1).

Table 1: Socio-demographic characteristics of respondents among nurses in public health institution of four woredas, West Arsi zone April, 2016 (N=185).

\begin{tabular}{llll}
\hline Variables & & No. & $(\%)$ \\
\hline Sex & Male & 131 & $(70.8)$ \\
\cline { 2 - 4 } Age (year) & Female & 54 & $(29.2)$ \\
\cline { 2 - 4 } & $20-24$ & 56 & $(30.3)$ \\
\cline { 2 - 4 } & $30-29$ & 103 & $(55.7)$ \\
\cline { 2 - 4 } & $35-39$ & 9 & $(4.86)$ \\
\cline { 2 - 4 } & $40-44$ & 9 & $(4.86)$ \\
\hline Qualification & Masters & 4 & $(4.3)$ \\
\cline { 2 - 4 } & Degree (B.Sc.) & 74 & $(40.0)$ \\
\cline { 2 - 4 } & Diploma & 107 & $(57.8)$ \\
\hline Marital status & Married & 103 & $(55.7)$ \\
\hline
\end{tabular}

\begin{tabular}{llll}
\hline & \multicolumn{1}{l}{ Single } & 79 & $(42.7)$ \\
\cline { 2 - 4 } Divorced & 3 & $(1.6)$ \\
\hline Religion & Orthodox & 44 & $(23.8)$ \\
\cline { 2 - 4 } & Muslim & 106 & $(57.3)$ \\
\cline { 2 - 4 } & Protestant & 34 & $(18.4)$ \\
\cline { 2 - 4 } & Other & 1 & $(0.5)$ \\
\hline Ethnicity & Oromo & 163 & $(88.1)$ \\
\cline { 2 - 4 } & Amhara & 16 & $(8.6)$ \\
\cline { 2 - 4 } & Others & 6 & $(3.2)$ \\
\hline
\end{tabular}

"Wakefata, ${ }^{* *}$ Gurage, Kambata, Zey

\section{Factors affecting the utilization of the IMNCI protocol among nurses in public health institution of four districts of West Arsi zone}

Fifty nine percent of the participants had less than five years experiences of servicing as health care providers. Of the total, the majority $80.5 \%$ of respondents had experience of working in under-five outpatient department. Regarding IMNCI training, more than half $57.8 \%$ of respondents had attended IMNCI training at different periods, out of which nearly half $51.35 \%$ of them had attended in service training. One hundred sixty five (89.2\%) of study participants had not received follow up training. Lack of trained staff $56.2 \%$, lack of supplies $37.3 \%$ and time consuming nature of the IMNC guideline 33\% were reported as the main factors hindering the utilization of IMNCI guidelines in the health institutions as shown in (Table 2).

Table 2: Distribution of factors affecting the utilization of the IMNCI protocol among nurses in public health institution of four districts, West Arsi zone April, 2016 ( $\mathrm{N}=185)$.

\begin{tabular}{llll}
\hline Variable & & No. & \multicolumn{1}{c}{$(\%)$} \\
\hline Year of service as nurses & $<5$ years & 110 & $(59.5)$ \\
\cline { 2 - 4 } & 6-10 years & 62 & $(33.5)$ \\
\cline { 2 - 4 } & $10-15$ years & 6 & $(3.2)$ \\
\cline { 2 - 4 } & $>15$ years & 7 & $(3.8)$ \\
\hline Served in under five OPD & Yes & 149 & $(80.5)$ \\
\cline { 2 - 4 } & No & 36 & $(19.5)$ \\
\hline Year of served in under five & 0-5years & 146 & $(78.9)$ \\
\cline { 2 - 4 } OPD & 6-10years & 2 & $(1.1)$ \\
\cline { 2 - 4 } & $>10 y e a r s$ & 1 & $(0.5)$ \\
\hline
\end{tabular}




\begin{tabular}{|c|c|c|c|}
\hline \multirow[t]{2}{*}{ Attended IMNCI training } & Yes & 107 & $(57.8)$ \\
\hline & No & 78 & $(42.2)$ \\
\hline \multirow{2}{*}{$\begin{array}{l}\text { Types of IMNCI training } \\
\text { attended }\end{array}$} & Pre service & 12 & $(6.48)$ \\
\hline & In service & 95 & $(51.35)$ \\
\hline \multirow[t]{2}{*}{ Received follow up training } & Yes & 20 & $(10.8)$ \\
\hline & No & 165 & $(89.2)$ \\
\hline \multirow{7}{*}{$\begin{array}{l}\text { Factors affecting utilization of } \\
\text { IMNCI guidelines }\end{array}$} & Shortage of staff & 30 & $(16.2)$ \\
\hline & Time consuming & 61 & (33) \\
\hline & Lack of supplies & 69 & $(37.3)$ \\
\hline & Untrained staff & 104 & $(56.2)$ \\
\hline & Lack of supervision & 51 & $(27.6)$ \\
\hline & Lack of knowledge & 16 & $(8.6)$ \\
\hline & $\begin{array}{l}\text { Lack of good } \\
\text { attitude }\end{array}$ & 22 & $(11.9)$ \\
\hline
\end{tabular}

\section{Multivariate analysis of factors affecting utilization IMNCI protocol by nurses in public health institutions in west Arsi zone}

In bivariate analysis, training [p value $0.001, \mathrm{COR}=2.9,95 \% \mathrm{CI}$ : $1.581,5.326$ ], lack of follow up training by facilitators [p value 0.031, $\mathrm{COR}=2.07,95 \% \mathrm{CI}: 1.07,4.04$ ], lack of supervision [p value $0.029, \mathrm{COR}=1.97,95 \% \mathrm{CI}$ : $1.071,3.64$ ], perception of IMNCI strategy as difficult to understand and apply [p value 0.01, $\mathrm{COR}=2.74,95 \% \mathrm{CI}: 1.27,5.89$ ], appreciation of rationale for IMNCI strategy by supervisors [p value $0.045, \mathrm{COR}=1.99$, 95\% CI: 1.02, 3.91], always referring IMNCI chart booklet [p value $0.014 \mathrm{COR}=2.112$, 95\% CI: 1.163, 3.832], and Always application of all stages of IMNCI [p value $0.004, \mathrm{COR}=25$, $95 \%$ CI: 1.33, 4.68] were found to be a candidate for multivariate logistic regression. However, among those variables which were found to be a candidate for multivariate analysis, only two variables were found to be significantly associated with the utilization of IMNCI protocols by nurses in public health institutions of West Arsi zone. None of the socio demographic variables were found to be the candidate for multivariate analysis. Training and always referring chart booklet were significantly associated with IMNCI utilization. The odd of IMNCI utilizations among nurses who had attended IMNCI training were 2.76 times higher compared to nurses who had not attended IMNCI training [AOR=2.76,95\% CI:1.388, 5.51]. Nurses who had practice of always referring chart booklet during every case management process were three times more likely to utilize IMNCI protocols $[\mathrm{AOR}=2.95$, 95\% CI: 1.48, 5.89] compared to their counterparts as shown in (Table 3).

Table 3: Bivariate and multivariate results of the factors Associated with IMNCI utilization by nurses in public health institution, West Arsi zone, April 2016, N=185.

\begin{tabular}{|c|c|c|c|c|c|c|}
\hline & & Yes & No & $\begin{array}{l}\text { COR } \\
\text { CI) }\end{array}$ & $(95 \%$ & $\begin{array}{l}\text { AOR }(95 \% \\
\text { CI) }\end{array}$ \\
\hline \multirow{2}{*}{$\begin{array}{l}\text { Attended } \\
\text { IMNCI } \\
\text { training }\end{array}$} & Yes & $\begin{array}{l}74 \\
(40 \%)\end{array}$ & $\begin{array}{l}33 \\
(17.8 \%)\end{array}$ & $\begin{array}{l}2.9 \\
5.36)\end{array}$ & (1.581, & $\begin{array}{l}2.76 \\
(1.388,5.51 \\
)^{*}\end{array}$ \\
\hline & No & $\begin{array}{l}34 \\
(18.4 \%)\end{array}$ & $\begin{array}{l}44 \\
(23.8 \%)\end{array}$ & 1 & & \\
\hline \multirow{2}{*}{$\begin{array}{l}\text { Lack } \\
\text { follow } \\
\text { training }\end{array}$} & Yes & $\begin{array}{l}68 \\
(36.8 \%)\end{array}$ & $\begin{array}{l}60 \\
(32.4 \%)\end{array}$ & $\begin{array}{l}2.076 \\
4.03)\end{array}$ & $(1.06$ & \\
\hline & No & $\begin{array}{l}40 \\
(21.6 \%)\end{array}$ & $\begin{array}{l}17 \\
(9.2 \%)\end{array}$ & 1 & & \\
\hline \multirow{2}{*}{$\begin{array}{l}\text { Lack of } \\
\text { supervision }\end{array}$} & Yes & $\begin{array}{l}57 \\
(30.8 \%)\end{array}$ & $\begin{array}{l}53 \\
(28.6 \%)\end{array}$ & $\begin{array}{l}1.97 \\
3.64)\end{array}$ & $(1.07$ & \\
\hline & No & $\begin{array}{l}51 \\
(27.5 \%)\end{array}$ & $\begin{array}{l}24 \\
(12.9 \%)\end{array}$ & 1 & & \\
\hline \multirow{2}{*}{$\begin{array}{l}\text { IMNCI is } \\
\text { difficult to } \\
\text { understand } \\
\text { and apply }\end{array}$} & Yes & $13(7 \%)$ & $\begin{array}{l}21 \\
(11.3 \%)\end{array}$ & & & \\
\hline & No & $\begin{array}{l}95 \\
(51.4 \%)\end{array}$ & $\begin{array}{l}56 \\
(30.3 \%)\end{array}$ & $\begin{array}{l}2.74 \\
5.89)\end{array}$ & $(1.27$ & \\
\hline \multirow{2}{*}{$\begin{array}{l}\text { My } \\
\text { supervisor } \\
\text { does not - } \\
\text { appreciate } \\
\text { rationale for } \\
\text { IMNCI }\end{array}$} & Yes & $\begin{array}{l}21 \\
(11.4 \%)\end{array}$ & $\begin{array}{l}25 \\
(13.5 \%)\end{array}$ & 1 & & \\
\hline & No & 87 (47\%) & $\begin{array}{l}52 \\
(28.1 \%)\end{array}$ & $\begin{array}{l}1.99 \\
3.91)\end{array}$ & $(1.02$ & \\
\hline \multirow{2}{*}{$\begin{array}{l}\text { Always } \\
\text { apply of all } \\
\text { stages of } \\
\text { IMNCI }\end{array}$} & Yes & $\begin{array}{l}82 \\
(44.3 \%)\end{array}$ & $\begin{array}{l}43 \\
(23.2 \%)\end{array}$ & $\begin{array}{l}2.5 \\
4.68)\end{array}$ & $(1.33$ & \\
\hline & No & $\begin{array}{l}26 \\
(14.1 \%)\end{array}$ & $\begin{array}{l}34 \\
(18.4 \%)\end{array}$ & 1 & & \\
\hline \multirow{2}{*}{$\begin{array}{l}\text { Always } \\
\text { referring } \\
\text { chart } \\
\text { booklet }\end{array}$} & Yes & $\begin{array}{l}62 \\
(33.5 \%)\end{array}$ & $\begin{array}{l}30 \\
(16.2 \%)\end{array}$ & $\begin{array}{l}2.112 \\
3.83)\end{array}$ & $(1.63$ & $\begin{array}{l}2.95(1.48 \\
5.89)^{* *}\end{array}$ \\
\hline & No & $\begin{array}{l}46 \\
(24.8 \%)\end{array}$ & $\begin{array}{l}47(25.4 \\
\%)\end{array}$ & 1 & & \\
\hline
\end{tabular}

" p value $<0.004,{ }^{* *} \mathrm{p}$ value $<0.014$

\section{DISCUSSIONS}

This study aimed to identify the utilization of IMNCI protocols and associated factors among nurses in public health institutions in four districts of West Arsi zone. The present study revealed that the proportion of IMNCI utilization was $58.4 \%$. This is below standard level established (above $68 \%$ ), by WHO and UNICEF [11]. The proportions of IMNCI utilization vary across different studies conducted in the world. For Example the utilization and application of IMNCI protocol in Kenya and China was approximately 14\% [11]. Other similar study conducted in Benin also reported that the proportion of utilizing of the guideline correctly varies from $15-88 \%$ [12]. The 
discrepancy observed between the utilization of the protocols estimated by several centers and countries might be due to the difference in distributions of the trained human resources, quality of care delivered by the centers, equipment, and socioeconomic status and as well as geographical locations.

The present study reported that the utilization of IMNCI guideline in the zones was hindered by many factors. For instances the odd of IMNCI guidelines utilization among nurses who had attended IMNCI training were 2.7 times higher compared to nurses who had not attended the training. Similarly nurses who had experience of always referring chart booklet during every case management process had three times higher odd of utilizing IMNCI protocols. This finding is almost consistent with studies conducted in other low resource setting country which indicated that IMNCI trained health workers were two times more likely to correctly classify illness and three times more likely to prescribe medication and treat the children [13-14].This implies training is the core factors in proper utilization of IMNCI guidelines. In other words the utilization of the IMNCI protocols would have been enhanced if the IMNCI training had been provided for all nurses who work in public health institutions. In present study the Practice of referring chart booklet was found to have association with IMNCI utilizations. This may be due to the reason that the nurses who were always referring chart booklet could learn how to utilize the IMNCI guidelines and also gain the skill and knowledge on how to utilize the guidelines.

Despite the significances of training for IMNCI utilization, only $57.8 \%$ of nurses in four districts of west Arsi zones had attended IMNCI training, which was less than WHO recommendation which stated that at least $60 \%$ of health care workers seeing sick children in the health facilities should trained how to utilize IMNCI guidelines [15]. However, the finding from present study was higher compared to similar study carried out in Indonesia [16]. The difference could be related to trained staff turnover and high cost of training.

This finding also reported that only $10.8 \%$ of participants had received follow up training. Despite Evidence suggests that follow up training is designed to improve supportive supervision skills such as methods for skill reinforcement, records review, assessment and enhancing job designs to encourage.

IMCI training and yolk bad environmental factors [11]. The present finding is lower than the figures (78\%) reported in studies conducted in Botswana and Tanzania $[9,17]$.

Health system related factor, which composed the factors like lack of supplies ,lack of supervision, frequent unavailability of IMNCI drugs and chart booklets, inadequate facility support were also listed by nurses as the others factors affecting utilization of IMNCI guidelines and this finding was also supported by another several comparable study conducted in different parts of the world [18-24].

Similarly in this finding, health workers related factors that affecting IMNCI utilization like shortage of the staff $16.2 \%$, lack of knowledge $8.6 \%$, and patient-nurse ratio $46 \%$ were also reported by the study participants. This was inconsistent with other studies, for instance study conducted in Indonesia and
Tanzania [15-16].This difference might be due to difference in economic status, study area and study period. However, this finding is consistent with other several similar studies carried out in Africa [9,18,20-28].

Time consuming nature of the protocol, protocol is too long, tedious and difficult to understand were also mentioned by the nurses as the protocol related factor that hamper the utilization of the guidelines. The present findings were also supported by various other comparable studies $[9,25,29]$.

In conclusions the proportion of IMNCI utilizations in the selected districts was low and less than the WHO recommendations. Training and frequent referring of chart booklet were found to have a significant association with the utilization of the IMNCI protocols. Therefore the emphasis should be given to the provision of IMNCI training to the nurse by the stakeholders in order to enhance proper utilization of the protocols and Further Large scale study with a representative sample size is recommended to be conducted in the future.

\section{LIMITATIONS}

First, as in all cross-sectional studies, we can infer association but not causation from our results.

Second, the finding of this study was limited to four districts of west Arsi zone and hence the findings cannot be generalized to the Oromia region or the country as a whole. Third the Other possible factors not adjusted for during the current study may influence observed associations.

\section{ACKNOWLEDGMENTS}

This study was funded by Addis Ababa postgraduate office. The authors are thankful to School of Allied Health Sciences, Addis Ababa University, For Its financial and technical support. Finally, our deep thanks extend to the research assistants who contributed to data collection.

\section{AUTHORS' CONTRIBUTIONS}

All authors made substantial contributions to conception and design, acquisition of data, or analysis and interpretation of data; took part in drafting the article or revising it critically for important intellectual content; gave final approval of the version to be published; and agree to be accountable for all aspects of the work.

\section{DISCLOSURE}

The authors declare that they have no competing interests in this work.

\section{REFERENCES}

1. UNICEF Integrated Management of Childhood Illness (IMCI) in the 21st Century: A Review of the Scientific and Programmatic Evidence 2016.

2. Gera T, Shah D, Garner P, Richardson M, Sachdev HS Integrated Management of Childhood Illness (IMCI) Strategy for children 
under fivel: effects on death, service utilization and illness. Cochrane 2012.

3. IMCI Maternal, newborn, child and adolescent health 2016.

4. $\mathrm{FMOH}, \mathrm{WHO} U$ Integrated management of newborn and childhood illness 2014.

5. Baum F, Earhart K. WHO South-East Asia 3: 123-195.

6. Titaley CR, Jusril H, Ariawan I, Soeharno N, Setiawan T, Challenges to the implementation of the integrated management of childhood illness (IMCI) at community health centres in West Java province, Indonesia. WHO South East Asia Journal of Public Health 3: 161-170 2014.

7. Snow J Health facility End-line Survey-synthesis report. Addis Ababa 2008.

8. Yamane T Statistics, an Introductory Analysis. 2nd edition. New York: Harper and Row 1967

9. Mupara LM (2013) Challenges identified by exprienced IMCI-1trained registered nurses in implementing the Integrated Management of Childhood Illness (IMCI) Stragey in Gabarone,Botswana 2013.

10. WHO Health Facility Survey. World Health 2003; 1: 1.

11. Silali MB Utilization of Integrated Management of Childhood Illnesses IMCI for Child health in Western Kenya 4: 102-114.

12. 12.Steinhardt LC, Onikpo F, Kouamé J, Piercefield E, Lama M. Predictors of health worker performance after Integrated Management of Childhood Illness training in Benin: a cohort study. BMC Health Serv Res. BMC Health Serv Res 2015; 15: 276.

13. Gouws E, Bryce J, Habicht J, Amaral J, Pariyo G. Improving antimicrobial use among health workers in first- level facilities: results from the Multi- Country Evaluation of the Integrated Management of Childhood Illness strategy. Bull World Health Organ 2006; 82: 509-515.

14. Nguyen DTK, Leung KK, McIntyre L, Ghali WA, Sauve R Does Integrated Management of Childhood Illness (IMCI) Training Improve the Skills of Health Workers? A Systematic Review and Meta-Analysis. PLoS One 8.2003.

15. Kiplagat A, Musto R, Mwizamholya D, Morona D Factors influencing the implementation of integrated management of childhood illness ( IMCI ) by healthcare workers at public health centers \& dispensaries in Mwanza , Tanzania. BMC Public Health 2014; 14: 277.

16. Titaley CR, Jusril H, Ariawan I, Soeharno N, Setiawan $T$. Challenges to the implementation of the integrated management of childhood illness (IMCI) at community health centres in West
Java province, Indonesia. WHO South East Asia J Public Health 2014; 3: 161-170.

17. Menas AF Factors influencing prescribers' aderance to IMCI guidelines in the management of pneumonia among under fives. Lind district, Tanzania 2007.

18. Mugala N, Mutale W, Kalesha P, Sinyinza E Barriers to implementation of the HIV guidelines in the IMCI algorithm among IMCI trained health workers in Zambia. BMC Pediatr 2010; 10: 93.

19. Manzi A, Magge H, Hedt-Gauthier BL, Michaelis AP, Cyamatare FR. Clinical mentorship to improve pediatric quality of care at the health centers in rural Rwanda: a qualitative study of perceptions and acceptability of health care workers 2014; 14: 275.

20. G Kitenge, I Govender Nurses 'monitoring of the Road to Health Chart at primary health care level in Makhado, Limpopo province S Afr Fam Pract 2014; 55: 275-280.

21. Victora CG, Adam T, Bryce J, Evans DB Integrated Management of the Sick Child 2006; 1177-1192.

22. Bharani S, Parmar T, Kantharia N, Parmar R Assessmentof the Implementation and Effectiveness of Imnci Program and Evaluation of Skills of Rural Anganwadi Workers in. Natl J Community Med 2012; 3: 207-212.

23. Vhuromu EN, Davhana-Maselesele M (2009) Experiences of primary health care nurses in implementing integrated management of childhood illnesses strategy at selected clinics of Limpopo Province Curationis 2009; 60-71.

24. Mullei K, Wafula F, Goodman C. A Case Study of Integrated Management of Childhood Illness (IMCI) Implementation in Kenya 2008.

25. Borghi J, Prosper H IMCI Implementation in Tanzania : Experiences, challenges and lessons 2009.

26. Febir LG, Baiden FE, Agula J, Delimini RK, Akpalu B. Implementation of the integrated management of childhood illness with parasitological diagnosis of malaria in rural Ghana: health worker perceptions. Malar J 2015;14: 174.

27. Walter ND, Lyimo T, Skarbinski J, Metta E, Kahigwa E. Why firstlevel health workers fail to follow guidelines for managing severe disease in children in the Coast Region, the United Republic of Tanzania 9Bull World Health Organ 2009; 99-107.

28. UNICEF Review of Systematic Challenges to the Scale-up of Integrated Community Case Management 2012.

29. Goga AE, Muhe LM Scaling up integration: workforce lessons from global child health strategy 2012;1: 50-54. 